\title{
Implementation Scenarios for 4D CAD in Practice
}

\author{
Marcel Broekmaat ${ }^{1}$, Bauke de Vries ${ }^{2}$ \\ ${ }^{1}$ Hollandse Beton Groep \\ Generaal Spoorlaan 489, 2285 TA Rijswijk \\ Postbus 81, 2280 AB Rijswijk \\ ${ }^{2}$ Eindhoven University of Technology, Department of Architecture, Building and Planning, \\ P.O. Box 513, 5600 MB Eindhoven, The Netherlands. \\ B.d.Vries@.tue.nl

\begin{abstract}
The application of 3D and 4D CAD software is considered to be able to offer possibilities for more consistent project documentation and visualisation, which should eventually enable fail cost reduction. 4D software is seen as a tool for project organisers and project team members to better communicate and analyse schedule information.. In this paper experiences with 4D CAD software in construction projects are discussed. Analyses of these experiences and additional user experiments have lead to a short-term and a long-term implementation strategy in practice.
\end{abstract}

KEYWORDS: 4D CAD, construction, simulation.

\section{INTRODUCTION}

Caused by the increasing complexity of construction projects, concurrent scheduling of building construction activities as well as insufficient project insight can result in inadequate schedules, which can induce problems during construction of a project, resulting in delays throughout the construction phase.

Besides that, parties, involved in projects, communicate in a way that is far from the most effective. Communication conflicts result in misunderstandings about responsibilities between parties, which can, subsequently, cause problems during construction.

The two distinguished problems concern project information analysis on the one hand and project information communication on the other hand. 4D software is thought to be able to support creation, analysis and communication of schedule information [Fischer, Kähkonen]. Therefore, application of 4D software might be a remedy for these issues; the research aimed to investigate the added value and shortcomings of application of 4D software at HBG, a construction company in the Netherlands.

\section{4D CAD}

4D software supports linking of 3D (CAD) geometry to one or more schedule activities, as reflected in Figure-1.

The result of an established link of 3D geometry representing building elements and schedule activities, is a simulation of the planned building process. The simulation enables analysis and communication of a schedule, as created by a project organiser.

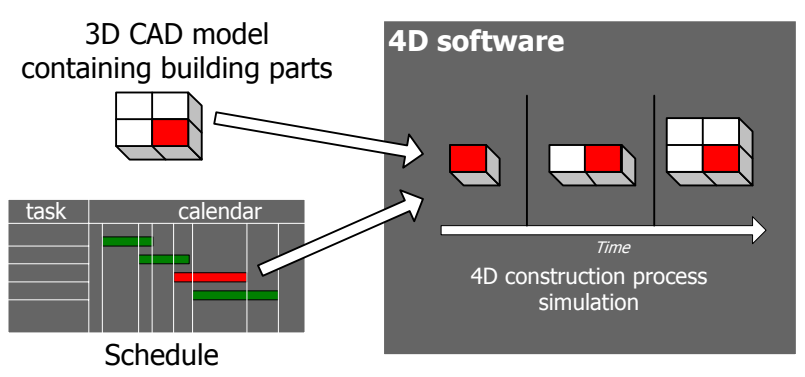

Figure 1: General description of $4 D$ software functionalitv

During the research, "Invizn", 4D software of Stanford University's Center for Integrated Software Engineering (CIFE), was used. The software features a VRML environment in which instances of 3D CAD geometry can be linked to schedule activities using 4D components.

4D components are defined in a user breakdown structure of the 3D model. Breaking down the 3D model following the construction breakdown as 
defined in the schedule, enables groupwise linking of schedule activities to the 4D components.

By defining activity types with a unique colour coding and consequently assigning them to schedule tasks, construction schedule activities are made recognisable, since the 3D geometry appears in the construction type colour when it is put in place.

\section{PARTICIPATORY RESEARCH}

Participating in a 3D/4D modelling process seemed to be the best way to discover benefits and problems in the use of 4D software. Two projects were used for this objective, namely a shipping centre in Rotterdam and a World Trade Centre in Amsterdam.

\section{$1^{\text {st }}$ application: Shipping centre Rotterdam}

During the project, extensive collaboration with the project organiser formed the basis for the creation of the first HBG 4D model. Tasks, that have been carried out in this collaborative 4D model creation consisted of: 3D modelling, scheduling, and 4D modelling. An important aspect of 3D modelling was how the 3D CAD model should be set up to "fit" to the schedule's breakdown. Vertical and horizontal divisions of the building model had to follow the construction order of the project. 3D modelling was finalised by exporting the model to a VRML format. Using AutoCAD, this required several steps. The actual 4D modelling - dragging and dropping 3D components and schedule activities into 4D components - was carried out by the project organiser.

In advance of the project start, there was a kickoff meeting, to explain the designed construction method to the foremen involved. During this meeting, the 4D simulation was shown to the attendees. In order to get reactions about the application of 4D software on "their" project, the auditors were asked to fill out a questionnaire. In this questionnaire they had to express the three most important construction issues in the project. The questionnaire had to be filled out twice: before and after seeing the 4D simulation.

The results of the questionnaire differed. Some people gave exactly the same answers before and after, but other people came up with other aspects of the construction process after they had seen the simulation.
The auditors were encouraged to give their opinion about the use of a 4D model in a discussion after the presentation of the simulation. During this discussion it became clear that most of those present were enthusiastic about the 4D model; some of them even had a wish for additive information in the model, e.g. to analyse security aspects of the construction process.

The use of 4D software in the Shipping centre project clearly indicated what constraints play a role in $4 \mathrm{D}$ modelling with regard to $3 \mathrm{D}$ modelling and schedule set-up. Also, the issue of naming of 3D and 4D components as well as schedule activities arose.

\section{$2^{\text {nd }}$ application: World Trade Centre Amsterdam}

The main attention of this project went out to the construction of the tower. The concrete core of the tower is constructed using hydraulic, self-climbing formwork. The construction of the core must have a lead of about 3 to 4 climbs on the construction of the slabs. This margin is needed to get enough space for the climbing process of the self-climbing formwork (space required for the hanging scaffold).

A rough schedule for the construction cycle was already made. The number of cranes that were needed for one climb was calculated using this rough schedule. A detailed schedule had still to be made.

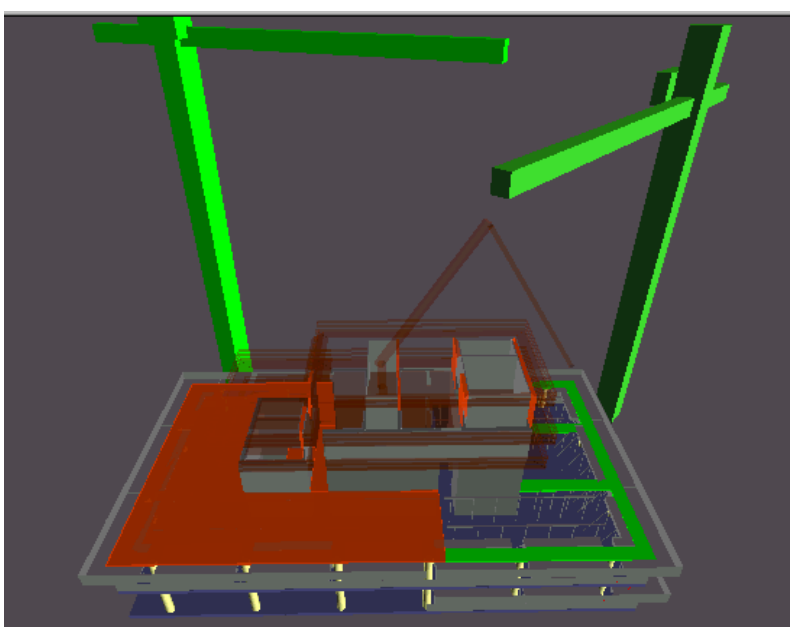

Figure 2: 4D simulation of WTC project

Because movement of temporary construction elements isn't supported by the 4D tool, it had to be simulated using a "appear - disappear" mechanism. This way of visualising movement requires a 3D representation of the equipment in every occurring situation (see Figure-2), resulting 
in large VRML files. Another requirement for the simulation of moving equipment is the introduction of activities that control the appearance and disappearance of the representation. This leads to an increased amount of activities in the project schedule, which, again, complicates the use of the schedule in the 4D tool. While creating the schedule for the construction cycles of the WTC project, a problem with the planning units was encountered. A construction cycle is set up using workdays and not calendar days; however, the time basis for the 4D tool is a calendar scale. The planning unit for detailed schedules (like a cycle planning) is often smaller than the smallest unit of the 4D tool, namely a day.

\section{Hands On Session}

In order to give HBG employees, involved in project management, a first impression of the functionality and benefits of 4D software, a "Hands On session" was organised. In this session, the attendees were informed about 4D research, the pilot project Shipping centre and expected future developments. To give the participants a "4D experience", a number of exercises were arranged.

The most important exercise was bifold: firstly, participants had to analyse a construction planning using only a bar chart and a set of drawings. Secondly, they could analyse the same project planning (with other errors in it) again, now facilitated with the 4D CAD system.

The result of this exercise proved the possible benefit of use of 4D software: the support of 4D CAD improved the quality of the analysis within the given time of 10 minutes. People got more motivated to answer the questions (more answers) and were able to do that quicker and more accurately (more correctly answered questions).

\section{3D/4D MODELLING PROCESS}

Experience in 4D software use was gained during participation in the research projects. This resulted in a description of "best practices" for 3D modelling and scheduling.

\section{D modelling}

Essential in the creation of a 4D model is the 3D modelling part. Based on the experiences, a flow chart has been set up (see Figure-3).

The modelling method is mainly determined by the answers on the questions (represented by spades in the flowchart):
1. Existing 3D model available?

2. Existing $3 \mathrm{D}$ model usable?

3. ADT model or "Traditional" 3D CAD model?

1. The first thing to do when there is a request for the creation of a $4 \mathrm{D}$ model for a project, is to contact involved parties to check whether there has already been made a 3D model of the project. Any available 3D information can support the 3D modelling process; even coarse .DXF wireframe models can give a good impression of dimensions and geometry.

2. At some moment, a decision must be made to either use the existing model or to start a new model from scratch. 3D models made by visualisation companies can be highly detailed, which isn't suitable for most 4D use purposes because it mostly unnecessarily slows down the eventual simulation.

3. Possibly available 3D models can be derived from several drafting and analysis software. Because Architectural Destktop (ADT) from Autodesk $^{\mathrm{TM}}$ is the standard drafting software within HBG, the ideal situation is when the existing model is created in ADT. In that case, the model can be adjusted and fine-tuned with the use of (specific HBG) ADT components and work methods. "Traditional" 3D CAD models ("wireframe" models) can also be used, but are more difficult to handle.

\section{Scheduling}

At the moment, scheduling and modelling, as well as scheduling and cost estimating are completely separate activities. Therefore, the "products" of these activities aren't geared to each other. The result of this "island"-like work method is that when 4D models have to be created, all the work concerning gearing the $3 \mathrm{D}$ model to the schedule is still to be done. With respect to this, consulting the project organiser in advance of the 3D modelling work is a way to prevent repeatedly rework.

\section{WORK METHOD QUADRANT}

Application of 4D software is not part of daytoday practice. UML use case scenarios and diagrams are used to describe current work method, current 4D supported work method and ideal 4D supported work method. Because its implementation causes changes in work methods, the SAP (HBG's financial and managing software) work method is also part of UML models. 
Placing the work methods in a quadrant (Figure-4) enables comparison of the UML models, which gives a view of required adjustments and additions in work method and software.

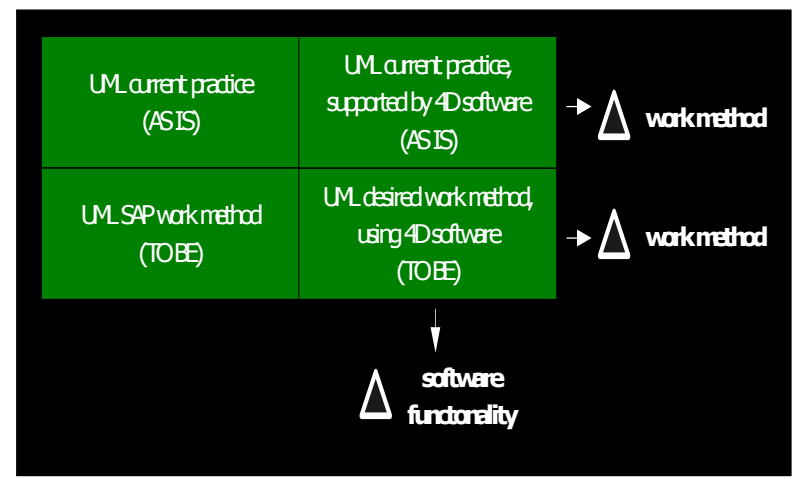

Figure 4: Variances between UML defined work methods

The work method in current project organising practice has been analysed in the first phase of the research; interviews with project organisers were held to clear up the current work method. SAP software brings about a business-oriented approach of project organising. The set up of a Work Breakdown Structure (WBS) is most important in the application of SAP for planning purposes.

The UML schemas in "current practice, using 4D software support" section give a description of current practice, based on results of interviews with project organisers and own experiences during participating research.

The work method for the use of 4D software as an extension on current practice features two main processes: creating a schedule and creating a $4 \mathrm{D}$ model. Important complaint on this work method is that the created $3 \mathrm{D}$ and/or $4 \mathrm{D}$ model can only be used after finishing it completely. Since 3D and/or 4D models can also be beneficial for project analysis in an early stage of a project, more integrated processes are desirable. This is reflected in the "desired work method".

\section{IMPLEMENTATION SCENARIOS}

The "desired" work method requires a reconstruction of the currently applied work $\operatorname{method}(\mathrm{s})$. Based on the UML schemas, two applicable transition scenarios are thinkable. These transition scenarios, reflected in Figure-5, implicate a long-term scenario and a short-term scenario.

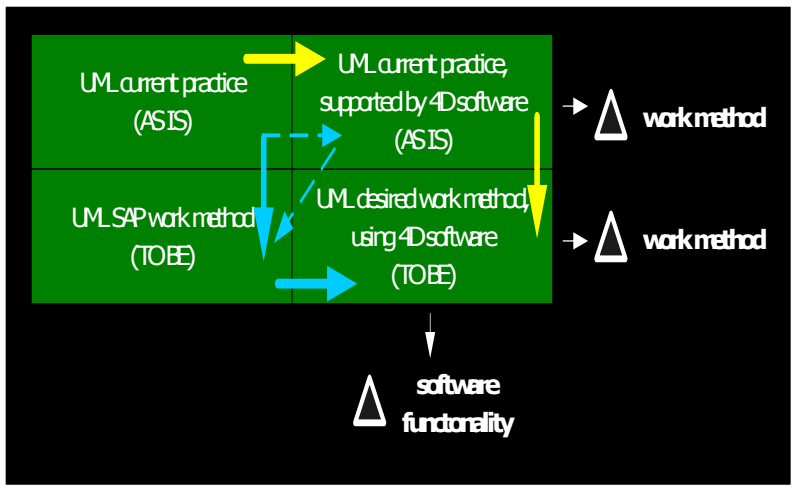

Figure 5: Transition scenarios: blue=long-term; yellow $=$ short-term

The short-term scenario is mainly based on currently available software tools that play a role in the project organising and $3 \mathrm{D} / 4 \mathrm{D}$ modelling process. Adding functionality and upgrading to database and integrated environment technologies reaches the eventual goal. Because the start of the short-term scenario can be at a short notice, it is most suitable for a quick distribution of the 4D software.

Consequently, adoption of 4D software as a new tool for project organisers and managers is feasible in the shortterm scenario. However, full integration is not possible because the applications will be developed separately.

A development strategy, based on SAP standards, will be a long-term scenario. In this scenario, data produced by the schedule application and ADT is stored in a SAP WBS. Schedules are made using SAP functionality. Upgrading the 4D software to database technology and linking it to the enterprise system (SAP) will result in a fully integrated environment. Additional data (resources, cost/budget and risk) can then be stored in the WBS part of concern. The link between ADT and the SAP WBS will be established by software, which enables conversion of ADT geometry to database records.

The best applicable next step to take will be to work out the currently feasible solutions, listed below.

- Simplified 3D CAD to VRML conversion - realised during the research;

- Naming convention, which ensures compatibility throughout the $2 \mathrm{D} / 3 \mathrm{D} / 4 \mathrm{D}$ modelling process of all model parts;

- Improved import and export functionality for schedules to eneasen the update of both 4D model and schedules; 
- Easy to use 3D sketch tool to enable fast creation of 3D models.

Particularly the naming convention is essential for further development and utilisation of the 4D supported work method. Naming is in itself closely related to classification, which is on ongoing research theme.

\section{CONCLUSIONS}

The proposed development of the software will only be effective when a more cooperative and integrated work method is introduced. A new approach, indicated by the HBG wide implementation of SAP software, might form a basis for the new work method [Broekmaat]. The way projects are organised greatly influences the opportunities for effectuation of (applicable) cooperative and integrated work methods. In this context, "design and build" organisation types seem most valuable.

\section{REFERENCES}

[Fischer] Martin Fischer, 4D Production Models: Research and Application. Department of Civil and Environmental Engineering Construction Engineering and Management Program, Stanford University, 1999.

[Kähkonen] Kalle Kähkonen en Jarko Leinonen, Improving Communication in Construction Projects with the Aid of Virtual Reality Technology. Proceedings of the $30^{\text {th }}$ Annual Project Management Institute, 1999 Seminars and Symposium, Philadelphia, Pennsylvania, USA.

Papers presented 10 october - 16 october 1999.

[Broekmaat] Marcel Broekmaat, The application of $4 D$ Construction Process Simulations in non residential projects, http://www.ddss.arch.tue.nl/projects, Thesis Eindhoven University of Technology, 2002. 


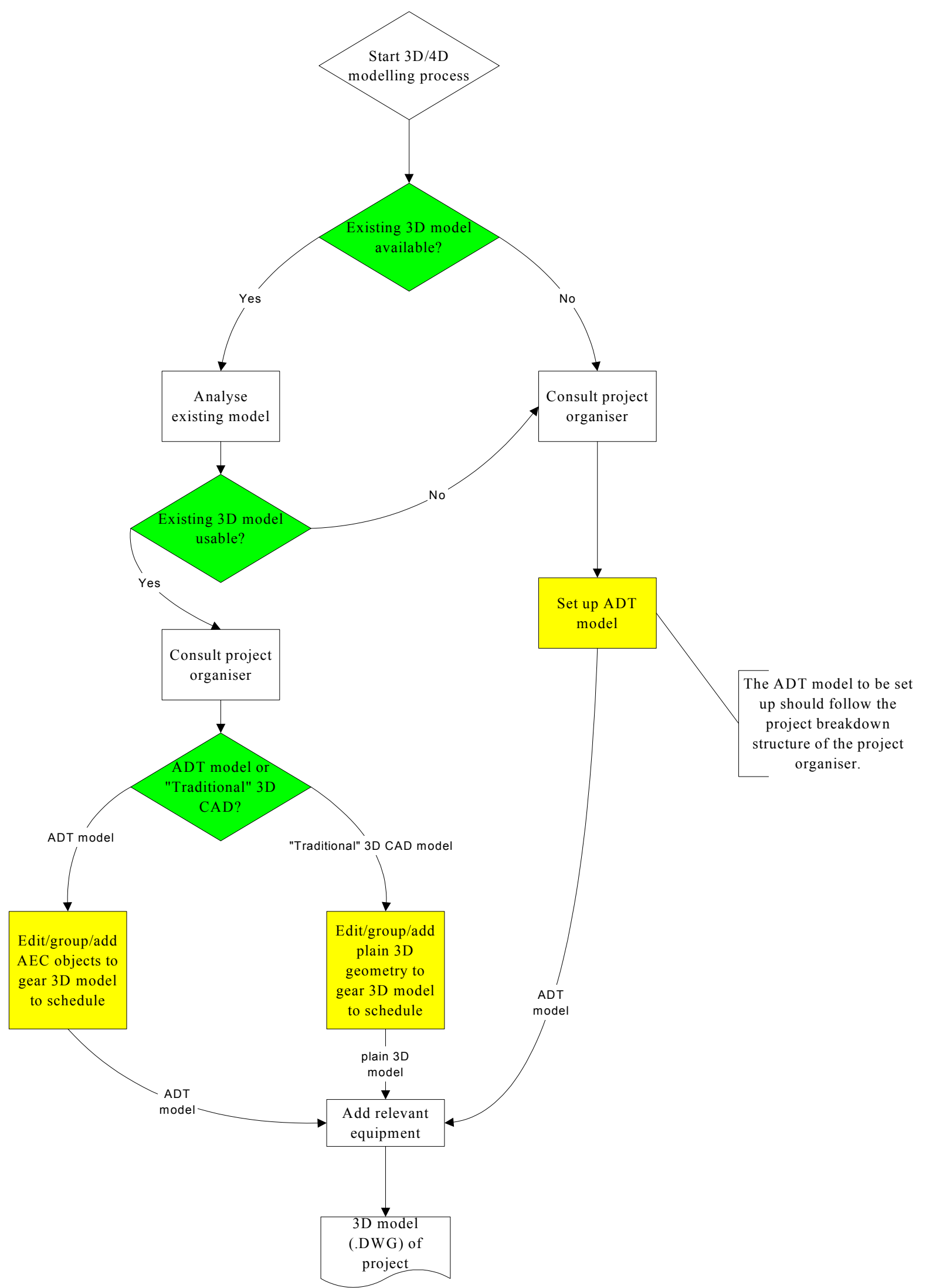

Figure - 3: flowchart of project 3D/4D modelling 